\title{
An investigation on plan geometries of RC buildings: with or without projections in plan
}

\author{
Tugba Inan*1, Koray Korkmaz ${ }^{1}$ and Ismail H. Cagatay ${ }^{2}$ \\ ${ }^{1}$ Izmir Institute of Technology, Department of Architecture, Izmir, Turkey \\ ${ }^{2}$ Cukurova University, Civil Engineering Department, Adana, Turkey
}

(Received April 16, 2011, Revised August 6, 2011, Accepted August 22, 2011)

\begin{abstract}
The interaction of plan geometry and structural configuration, a determinative factor in the earthquake behavior of buildings, has become a serious issue in the building industry in Turkey due to the poor seismic performance of $\mathrm{R} / \mathrm{C}$ buildings during the latest earthquake. Consequently, designing new buildings without structural irregularities against earthquake loads is proving to be more significant. This study focuses on the effects of plan geometries on earthquake performances of buildings. In that respect, structural irregularities in the plan are investigated in detail based on the Turkish Earthquake Code (TEC 2007). The study is based on five main parametric models and a total of 40 sub-models that are grouped according to their plan geometries with excessive projections such as L-shaped, H-shaped, T-shaped and U-shaped models. In addition to these, a square model without any projections is also generated. All models are designed to have the same storey gross area but with different number of storeys. Changes in the earthquake behavior of buildings were evaluated according to the number of storeys, the projection ratios and the symmetry conditions of each model. The analysis of each structural irregularity resulted in many findings, which were then assessed. The study demonstrates that the square model delivers the best earthquake performance owing to its regular plan geometry.
\end{abstract}

Keywords: earthquake; architectural form; projections; structural irregularities.

\section{Introduction}

Turkey, with more than $90 \%$ of its territory situated in highly seismic regions, is an earthquake prone country that has been struck by numerous devastating earthquakes throughout history. 21 earthquakes took place with magnitudes greater than 7 over the last century, taking the lives of more than 80,000 people and destroying or heavily damaging 500,000 buildings (Cagatay 2005). Earthquakes happening at frequent intervals not only cause considerable loss of life and property but have also negative impacts on the national economy (Sezen et al. 2000). As a result, designing earthquake resistant buildings that withstand earthquake loads is extremely important.

All modern earthquake codes recommend that the design and construction of irregular buildings should be avoided. Today the vast majority of Turkey's urban population lives in multi-storey reinforced concrete $(\mathrm{R} / \mathrm{C})$ apartment blocks that have a variety of structural irregularities. The greater part of the built environment consists of typical five-storey $\mathrm{R} / \mathrm{C}$ buildings. The building damage survey conducted after the 1999 Marmara Earthquake in order to correlate damage level and building height shows that building vulnerability increases remarkably with the number of storeys. Especially four and

\footnotetext{
* Corresponding author, Research assistant, E-mail: tugbainan85@gmail.com
} 
five-storey buildings appear to be more vulnerable than others (Sucuoğlu and Y1lmaz 2000). The tendency to construct high-rise buildings, especially in industrial cities, has resulted with an increase in the number of high-rise buildings with 20 -storeys or more.

Turkish Earthquake Code (TEC 2007) (Specification for Buildings to be Built in Seismic Zones 2007) is a contemporary earthquake standard and recommends that the design and construction of irregular buildings should be avoided. It states that structural systems should be arranged symmetrically or almost symmetrical in plan and that torsional irregularity should preferably be avoided. This makes it essential to use stiff structural elements so as to increase the torsional stiffness of the building (Repapis et al. 2006, Stefano et al. 2008). For this reason, earthquake resistant building design is not a simple procedure but one that is affected by many parameters, such as the dimensions of height and plan, the type of the structural system, the distribution of partition walls, the selection of the structural system, distribution of mass and rigidities of a building, all of which significantly impact earthquake safety (Tezcan 1998, Charleson 2008).

Earthquake behavior of reinforced concrete structures aiming to prevent structural irregularities has always been a subject extensively addressed by numerous researchers (Zacek 2002, Dimova and Alashki 2003, Ganjavi et al. 2007, Aziminejad and Moghadam 2005, Athanassiadou 2008, Belmouden and Lestuzzi 2009, Cagatay 2010). They have investigated the effect of torsional irregularity of a series of walled and framed sample structures with different shear wall configurations under earthquake loading and concluded that the maximum torsional irregularity values are observed when both the number of axes and the number of storeys are low.

Investigation of numerous collapsed or heavily damaged multi-storey $\mathrm{R} / \mathrm{C}$ buildings following the recent earthquake in Turkey shows that the causes of damage are directly or indirectly related with torsional and soft storey irregularities developed during the architectural design process (Tezcan and Alhan 2001). Selecting the best possible structural frame and providing security measures against an earthquake is in the interest of not only civil engineers but also architects. Architects, however, rather than deal with strength and stresses against loads such as those produced by an earthquake, are generally interested in the functional use and the aesthetics of structures (Cagatay 2009).

The interaction between architectural design and structural configuration determines the behavior of structures against earthquake loads. Failure in the architectural design phase cannot be remedied by calculations or detailed structural designs performed subsequently by the structural engineer. A seismically well-arranged architectural design is necessary in order to withstand devastating earthquake loads (Charleson 2008).

This study compares regular plan geometry and irregular plan geometry in terms of their earthquake behavior with regards to structural irregularities. This is a significant issue because the same damage picture emerges after each earthquake, but in each case it is forgotten afterwards. The effects of the number of storeys, symmetry axes and projection dimension ratios are evaluated based on the TEC-2007.

\section{Importance of architectural design in terms of structural behaviour}

There is a strong relationship between the architectural design of a building and its structural behavior during an earthquake. Architectural design decisions have a significant effect on the earthquake behavior of a structure because the building and structural system configurations of a structure heavily influence its seismic performance (Cagatay 2010). Architectural principles for an 
earthquake resistant building cannot be inserted by the structural engineer after the completion of an architectural design; they need to be applied during the design phase. Therefore, earthquake resistant design should not be viewed solely as an issue of engineering calculations.

In the best possible conditions, an earthquake resistant ideal design calls for a number of processes from the beginning of an architectural design until the construction of the building. It requires that the total service loads that will act on a building be determined during the design phase, following which a suitable design must be reached that is in accordance with the local codes and standards by modeling the structure in relation with the real structure (Cagatay 2009).

The architect determines the structural system of a building based on the requirements of the architectural design and then the structural engineer designs the proper structural system. However, if the structural system is not earthquake resistant, there is very little the structural engineer can do to improve the system.

\section{Structural irregularities}

The definition of irregular buildings, whose design and construction should be avoided due to their unfavorable seismic behavior and types of irregularities in plan and elevation, is stated in the TEC-2007. Accordingly, TEC-2007 divides them into two main groups: irregularities in plan and irregularities in the vertical direction. Irregularities in plan consist of three different types of structural irregularities, which are torsional irregularity denoted as A1, floor discontinuities denoted as A2 and projections in plan denoted as A3. Irregularities in the vertical direction comprise three types of structural irregularities, which are weak storey denoted as B1, soft storey denoted as B2 and discontinuity of structural elements denoted as B3.

In the TEC-2007, methods to be used for the seismic analysis of buildings and building-like structures are Equivalent Seismic Load Method, Mode-Superposition Method and Analysis Methods in the Time Domain. While the application limits of the Equivalent Seismic Load Method depends on the irregularity types A1, B2 and total height limits, the last two methods may be used for the seismic analysis of all buildings and building-like structures.

\subsection{Torsional irregularity (A1)}

The following is the case where torsional irregularity factor $\eta_{b i}$ (defined for any of the two orthogonal earthquake directions as the ratio of the maximum storey drift at any storey to the average storey drift at the same storey in the same direction) is greater than 1.20 (refer to Fig. 1).

$$
\eta_{b i}=\frac{(\Delta i) \max }{(\Delta i) a v g}>1.2
$$

Torsional irregularity occurs in a structure when the torsional irregularity coefficient $\left(\eta_{b i}\right)$ is greater than 1.20 at any storey of the structure. The $\pm 5 \%$ additional eccentricity is considered in the displacement computations on both earthquake directions.

The eccentricities which determine the torsional irregularity coefficients are illustrated in Fig. 2. The existing eccentricity of the system is symbolized by $e_{s}$. In the calculations, $\pm 5 \%$ additional coefficient is taken into consideration in order to calculate the additional eccentricity, which is denoted as $e_{a d}$. This additional eccentricity is at first multiplied with the dimension of the building 


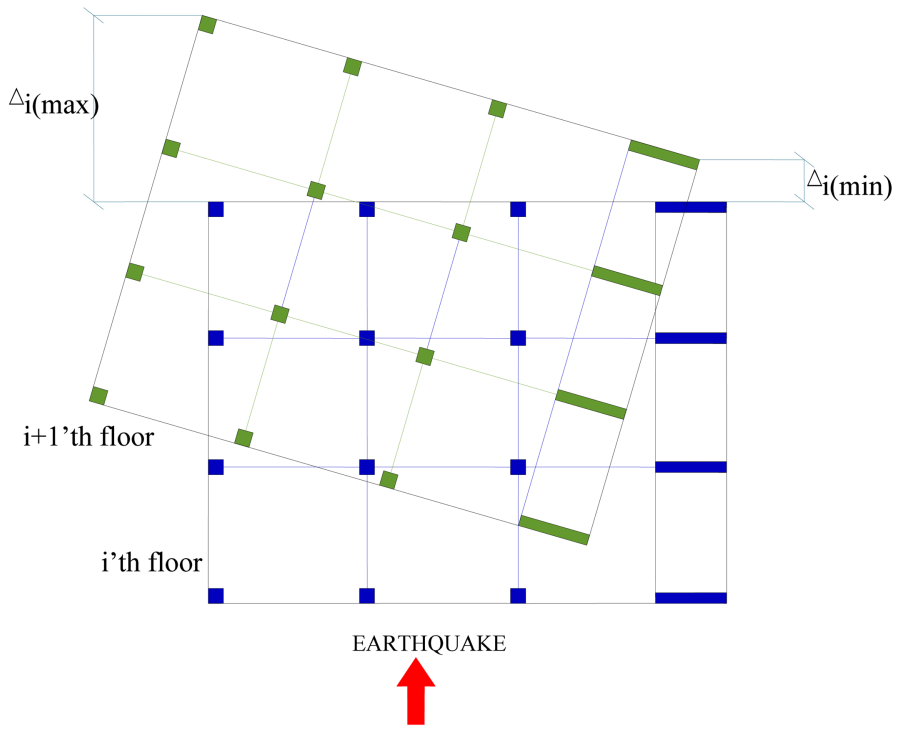

Fig. 1 Torsional irregularity

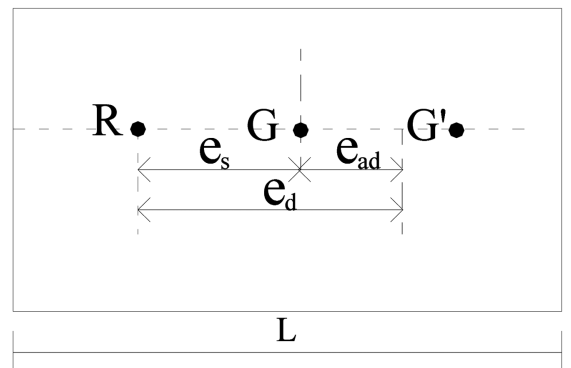

(a)

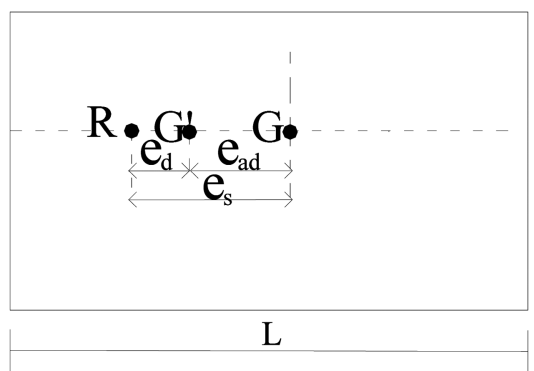

(b)

Fig. 2 Design eccentricity: (a) $+5 \%$ additional eccentricity and (b) $-5 \%$ additional eccentricity

that is parallel to the earthquake direction. Then, the result is summed with the existing eccentricity of the system. This eccentricity is called the design eccentricity and is denoted as $e_{d}$. The torsional irregularity is calculated based on this eccentricity. If the torsional irregularity coefficient of $\eta_{b i}$ is between 1.20 and 2.00, the eccentricity is increased by a factor, denoted as $D i$ in the following formula, and the earthquake analysis is repeated (TEC 2007).

$$
D_{i}=\left(\eta_{b i} / 1.2\right)^{2}
$$

In any floor plan, the distance between the center of gravity denoted as $G$ and the centre of rigidity denoted as $R$ should be kept as minimum as possible (Charleson 2008, Inan 2010). The rigidity centre is described as the centre of vertical structural elements. The gravity center is the centre of the whole building. It covers slab, beams, walls and live loads except vertical structural elements. While the center of gravity of the structure is affected by earthquake loads, the rigidity center of the structure reacts to these loads. If the eccentricity between these two centers is great, a torsional moment occurs around the center of rigidity and the structure begins to rotate around the rigidity axis (Fig. 3). This torsional moment creates additional shear forces. There are many buildings 


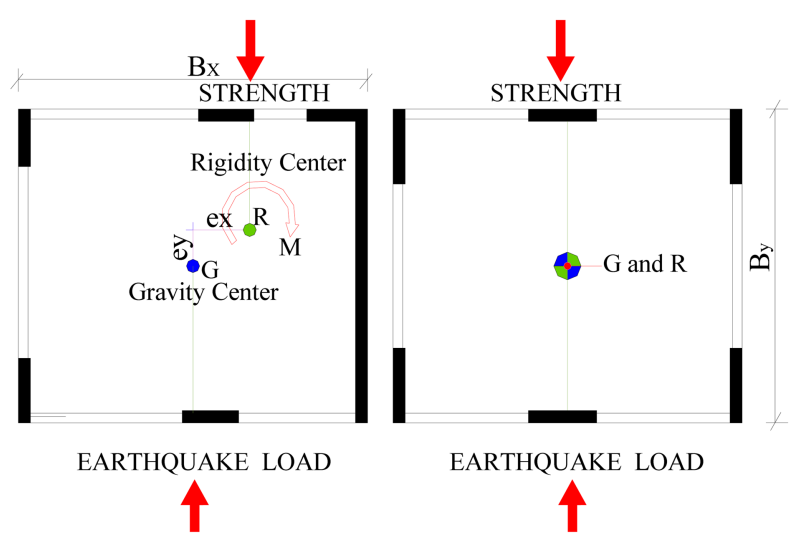

Fig. 3 Working mechanism of the gravity and rigidity centre

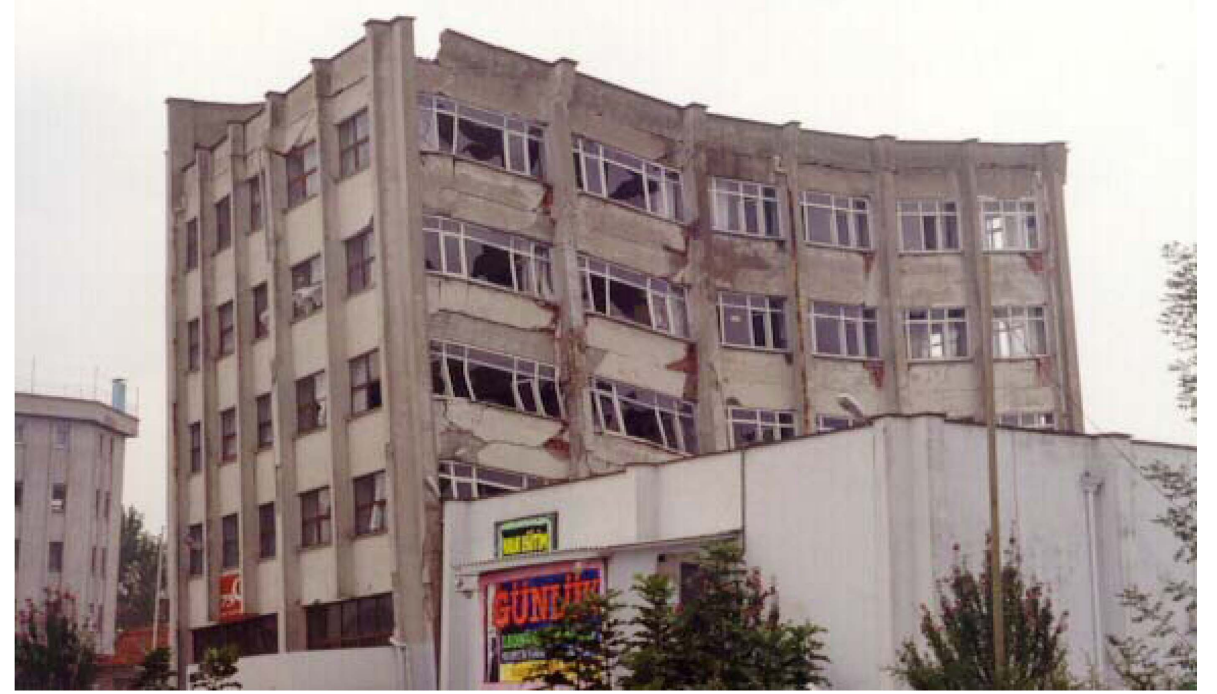

Fig. 4 A building heavily damaged during Marmara earthquake, Turkey in 1999 due to torsional irregularity

damaged during an earthquake due to torsional effect, as seen in Fig. 4.

\subsection{Interstorey stiffness irregularity (Soft storey) (B2)}

B2 type irregularity is defined in the TEC-2007 as the case where in each of the two orthogonal earthquake directions the stiffness irregularity factor $\eta_{k i}$, which is defined as the ratio of the average storey drift at any storey to the average storey drift at the storey immediately above or below, is greater than 2.00 . Storey drifts need to be calculated considering the effects of the $\pm 5 \%$ additional eccentricities.

$$
\eta_{k i}=\left(\Delta_{i} / h_{i}\right)_{\mathrm{ave}} /\left(\Delta_{i+1} / h_{i+1}\right)_{\mathrm{ave}}>2.0 \text { or }
$$




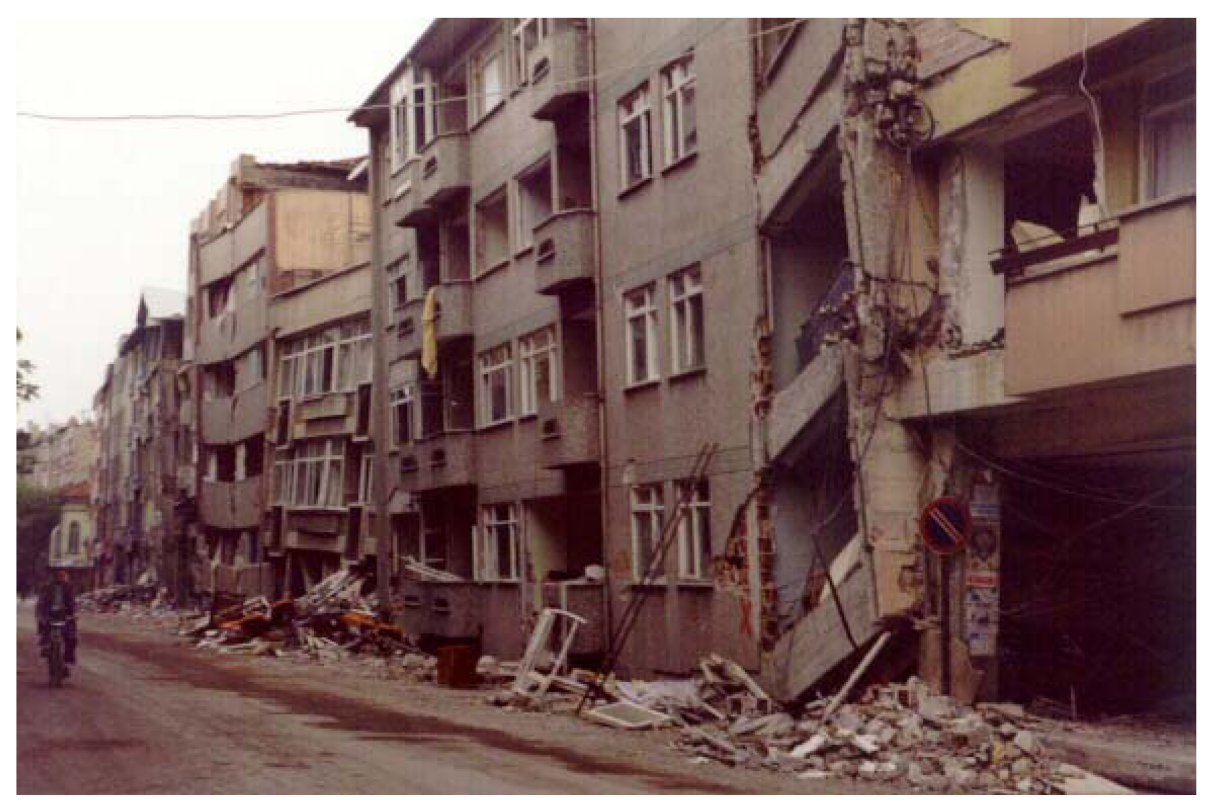

Fig. 5 Soft storey effect in buildings during Marmara earthquake, Turkey (1999)

$$
\eta_{k i}=\left(\Delta_{i} / h_{i}\right)_{\mathrm{ave}} /\left(\Delta_{i-1} / \mathrm{h}_{i-1}\right)_{\mathrm{ave}}>2.0
$$

where $\Delta_{i}$ represents storey drift of $i$ 'th storey of building and $h_{i}=$ height of $i$ 'th storey of building.

\section{Numerical analysis}

The study involves the evaluation of structural irregularities in relation with the TEC-2007. Many parametric studies were developed for this purpose. Changes in parameters, such as torsional irregularity coefficient $\left(\eta_{b i}\right)$, stiffness irregularity coefficient $\left(\eta_{k i}\right)$, maximum effective storey drift, inter-storey drift and second order effect are compared in each parametric model.

All models are designed to have the same storey gross area but with different number of storeys and plan geometries. Variations in the earthquake behavior of buildings are evaluated according to the number of storeys, projection ratios and symmetry conditions of the models. The aim is to explore the effective role of the building's plan geometry, its regularity, projection ratios and symmetry axes in determining earthquake behavior of structures with the same rigidity distribution and same floor gross area. Generated based on defined variables, all models are compared in terms of their earthquake behavior on the basis of their structural irregularities, following which obtained results are discussed.

The study consists of five main parametric models of different plan geometries, incorporating a total of 40 sub-models. Each model has a beam span of $5 \mathrm{~m}$ with different number of bays in both $\mathrm{X}$ and $\mathrm{Y}$ directions with the floor gross area of $400 \mathrm{~m}^{2}$. They are designed with $C 30$ class concrete and $S 420$ class steel, where each model is assumed to be in the $1^{\text {st }}$ degree earthquake zone. Project and TEC-2007 parameters, which are used in the cases, are described in the Table 1 as follows:

The main variables can be listed as follows: 
Table 1 Project and TEC-2007 parameters

\begin{tabular}{ll}
\hline \multicolumn{1}{c}{ Project parameters of the models } & \multicolumn{1}{c}{ TEC-2007 Parameters } \\
\hline Maximum storey number: 20 & Earthquake zone: 1 \\
Storey height: $2.80 \mathrm{~m}$ & Soil class: $Z 2$ \\
Maximum building height $(H n): 56 \mathrm{~m}$ & Earthquake zone factor: 0.4 \\
Beam span: $5 \mathrm{~m}$ & Building importance factor: 1 \\
Beams: $30 / 60 \mathrm{~cm}$ & Concrete class: $C 30$ \\
Columns: $60 / 60 \mathrm{~cm}$ & Steel class: $S 420$ \\
Slab thickness: $15 \mathrm{~cm}$ & Ductility level: High, $R: 6.00$ \\
& Live load factor $: 0.3$ \\
\hline
\end{tabular}

- The number of storey $(1 S, 3 S, 5 S, 8 S, 10 S, 12 S, 15 S, 20 S)$

- Plan geometry

- Projection ratio

All models are analyzed with "IdeCAD" (IdeCAD 2010), which is a 3D structural analysis software for reinforced concrete structures that integrates design and detailing while covering all stages related with reinforced concrete structures from dynamic analyses (Takashi 2011) to design of reinforced concrete cross-sections. This structural software was chosen for this study as it presents a common platform between structural engineers and architects that enables collaboration. All the necessary controls are made in accordance with the TEC-2007 and the building code requirements for reinforced concrete, TS-500 (2000).

\subsection{Model A: L plan geometry}

In this model, the storey gross area is $400 \mathrm{~m}^{2}$ and the plan geometry of the structure is designed as an L-shaped frame system (Fig. 6). Each beam span has a length of $5 \mathrm{~m}$. A3 irregularity or projections in plan is described in the TEC-2007 as the cases "where the projections in both of the

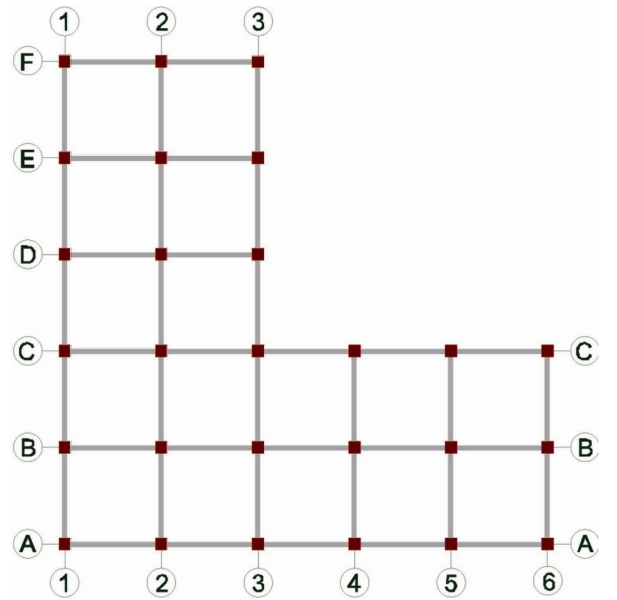

Fig. 6 Structural plan of parametric Model A 
Table 2 Obtained results from the analysis

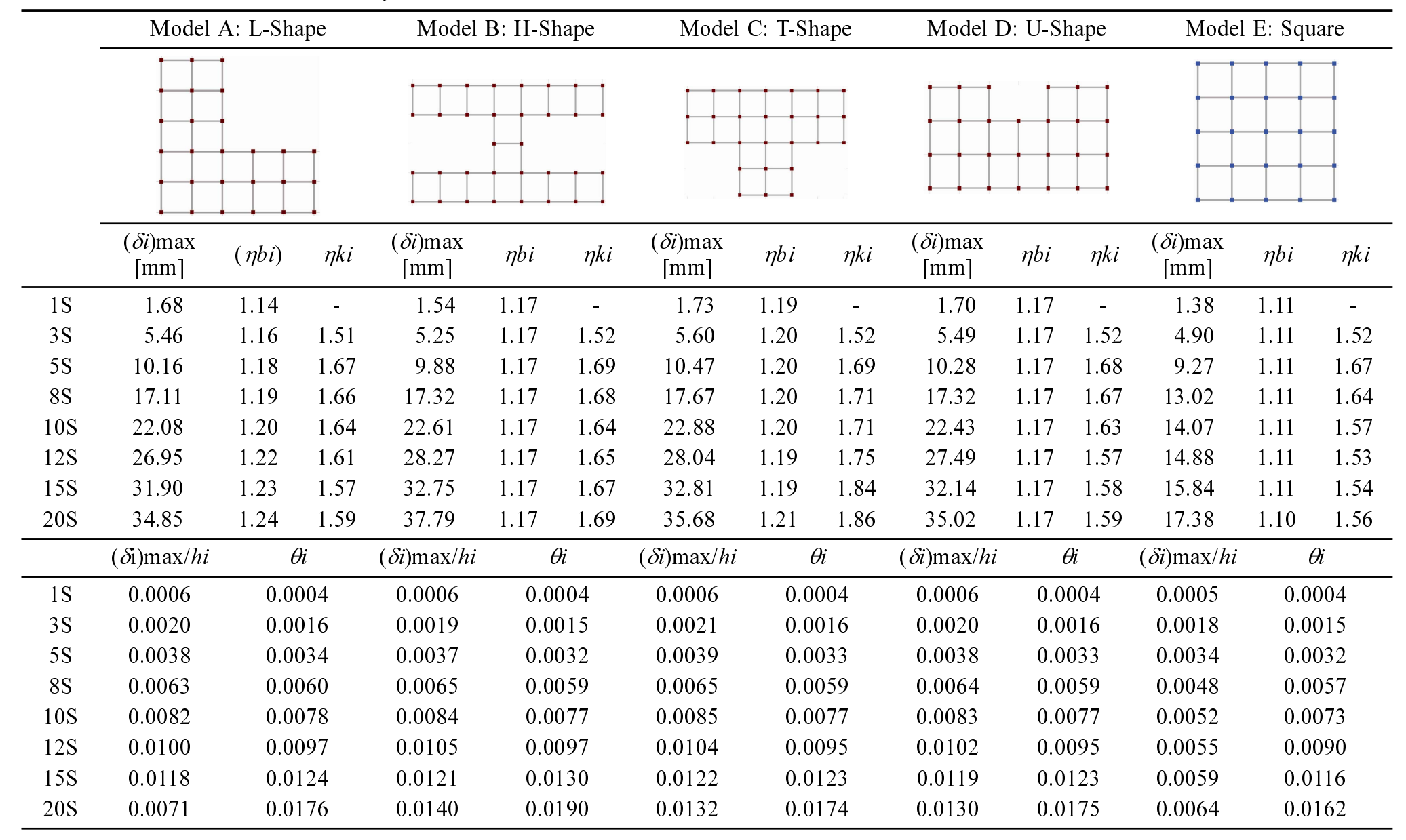


two directions exceed the total plan dimensions of the structure in the respective directions by more than 20\%". The plan geometry in this model has the same projection dimensions on both axes, which is $15 \mathrm{~m}$, with the total plan dimensions of $25 \mathrm{~m}$ on both $\mathrm{X}$ and Y-direction. The A3 ratio in the L-shaped parametric model is calculated as $60 \%$ on the both direction. Consequently, as the limit ratio is exceeded, there is an A3 irregularity in the L-shaped parametric model (Model A) based on both axes. This model is nonsymmetrical with respect to both axes. However, it has a diagonal symmetry axis which passes through the intersection of 1-1 and A-A axes together with 66 and F-F axes.

The analysis shows that the maximum value of effective storey drift in the L-shaped parametric model varies between $1.68 \mathrm{~mm}$ and $34.85 \mathrm{~mm}$. The limit values in terms of interstorey drifts and second order effect are not exceeded. These values increase from the one-storey model to the 20storey model

Based on the analysis report (refer to Table 2), the torsional irregularity coefficients $\left(\eta_{b i}\right)$ vary between 1.14 and 1.24. The most critical value is noticed as 1.24 in the 20 -storey sub model of the L-shaped structure (Model A). As the limit value of 1.20 is exceeded, there is torsional irregularity in this structure. Torsional irregularity coefficients not only increase from the one-storey model to the 20-storey model, but they also increase within the storeys of each sub-model of the L-shaped structure (Model A) - for ex. the values are higher on the $5^{\text {th }}$ floor of a 5 -storey model than its $1^{\text {st }}$ floor.

Stiffness irregularity coefficient or soft storey irregularity coefficient $\left(\eta_{k i}\right)$ is within the normal ranges in the sub models of the L-shaped parametric model, ranging between 1.51 and 1.67. As the coefficients remain under the limit coefficient of 2.00, the soft storey coefficient is agreeable. The highest soft storey irregularity coefficient is calculated as 1.67 in the five-storey sub-model of Lshaped structure (Model A). It is observed on the first storey of the L-shaped parametric model. On the other hand, there is not a balanced increase or decrease within the storeys of each of the different storey parametric models of the L-shaped structure from the ground floor to the upper floors.

\subsection{Model B: H plan geometry}

In this model, the storey gross area is $400 \mathrm{~m}^{2}$ and the plan geometry of the structure is designed

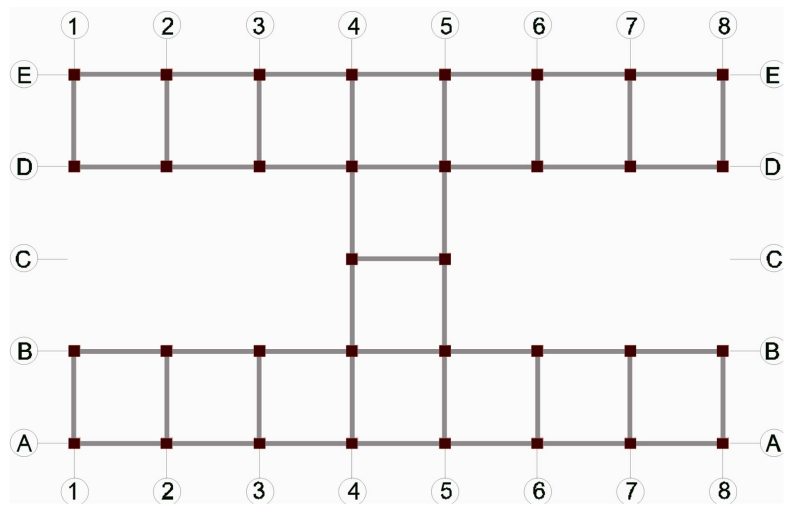

Fig. 7 Structural plan of parametric Model B 
as a H-shaped frame system (Fig. 7). Each beam span has a length of $5 \mathrm{~m}$. The plan geometry in this model has $15 \mathrm{~m}$ projection dimension on the X-axis while there is no projection on the Y-axis. The total plan dimensions of the model are $35 \mathrm{~m}$ on the X-direction and $20 \mathrm{~m}$ on the Y-direction. The A3 ratio in the $\mathrm{H}$-shaped parametric model is calculated as approximately $43 \%$ on the $\mathrm{X}$-axis. Consequently, as the limit ratio is exceeded, there is an A3 irregularity in the H-shaped parametric model (Model B) based on the X-axis. Furthermore, this model is symmetrical with respect to both axes.

The analysis demonstrates that the maximum value of effective storey drift in the H-shaped parametric model varies between $1.54 \mathrm{~mm}$ and $37.79 \mathrm{~mm}$. The limit values in terms of interstorey drifts and second order effect are not exceeded. These values increase from the one-storey model to the 20-storey model.

Based on the analysis, the maximum torsional irregularity coefficient $\left(\eta_{b i}\right)$ of 1.17 is obtained in the all sub models of $\mathrm{H}$-shaped structure. Therefore, there is no torsional irregularity in this model. It is also observed that there is not an increase or a decrease in the maximum torsional irregularity coefficients from the one-storey model to the 20-storey model. However, these coefficients decrease within the storeys of each sub-model of the $\mathrm{H}$-shaped structure (Model B).

Stiffness irregularity coefficient or soft storey irregularity coefficient $\left(\eta_{k i}\right)$ is within the normal ranges in the sub-models of the H-shaped structure, ranging between 1.52 and 1.69 . The soft storey coefficient is acceptable because the coefficients remain under the limit coefficient of 2.00. The highest soft storey coefficient is calculated as 1.69 in the five-storey sub-model of the parametric Model B. It is observed in the $1^{\text {st }}$ storey of the H-shaped structure. Moreover, it is also observed that there is not a balanced increase or decrease in the highest soft storey irregularity coefficients from one-storey model to the 20-storey model.

\subsection{Model C: T plan geometry}

In this model, the storey gross area is $400 \mathrm{~m}^{2}$ and the plan geometry of the structure is designed as a T-shaped frame system (Fig. 8). Each beam span has a length of $5 \mathrm{~m}$. The plan geometry in this model has the same projection dimensions on both axes, which is $10 \mathrm{~m}$, with the total plan

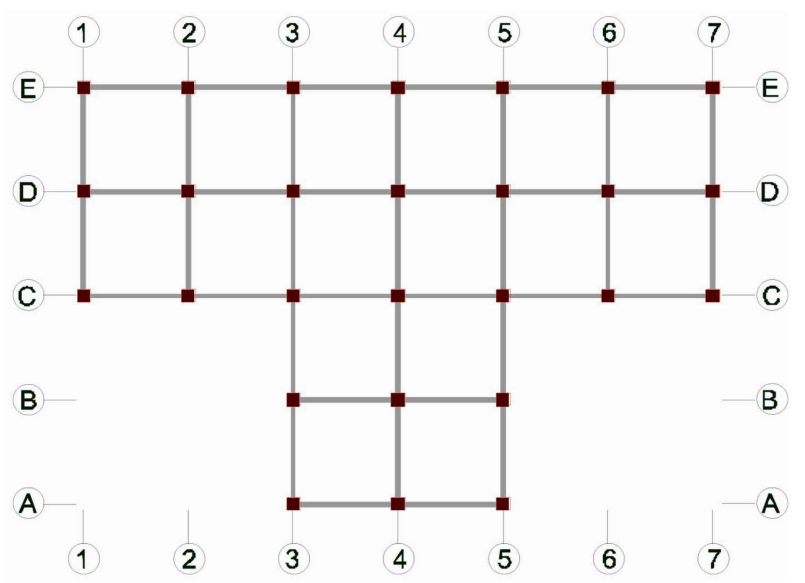

Fig. 8 Structural plan of parametric Model C 
dimensions of $30 \mathrm{~m}$ on the X-direction and $20 \mathrm{~m}$ on the Y-direction. The A3 ratio in the T-shaped parametric model is calculated as approximately $33 \%$ on the $\mathrm{X}$-axis while it is $50 \%$ on the Y-axis. Consequently, as the limit ratio is exceeded, there is an A3 irregularity in the T-shaped parametric model (Model C) based on both axes. On the other hand, this model is symmetrical with respect to only the Y-axis.

The analysis demonstrates that the maximum value of effective storey drift in the T-shaped parametric model varies between $1.73 \mathrm{~mm}$ and $35.68 \mathrm{~mm}$. The limit values in terms of inter-storey drifts and second order effect are not exceeded. These values not only increase from the one-storey model to the 20-storey model, but they also increase within the storeys of each sub-model of the Tshaped structure (Model C).

According to the analysis report (refer to Table 2), the highest torsional irregularity coefficient $\left(\eta_{b i}\right)$ of 1.21 is obtained in the 20-storey sub model of the T-shaped structure (Model C), which shows that there is a torsional irregularity in the T-shaped parametric model. It is also observed that there is not a balanced increase or decrease in the maximum torsional irregularity coefficients.

Stiffness irregularity coefficient or soft storey irregularity coefficient $\left(\eta_{k i}\right)$ is within the normal ranges in the sub-models of the T-shaped structure, ranging between 1.52 and 1.86 . The soft storey coefficient is agreeable because the coefficients remain under the limit coefficient of 2.00 . The highest soft storey coefficient is calculated as 1.86 in the 20 -storey sub-model of the T-shaped structure. The highest soft storey coefficients are observed in the $1^{\text {st }}$ storey. Furthermore, it is observed that if the number of storeys in the T-shaped parametric model increases, the maximum soft storey irregularity coefficient will gradually increase in each of the different storey sub-models of the T-shaped structure. On the other hand, there is not a balanced increase or decrease within the storeys of each of the different storey parametric models of the T-shaped structure from the ground floor to the upper floors.

\subsection{Model D: U plan geometry}

In this model, the storey gross area is $400 \mathrm{~m}^{2}$ and the plan geometry of the structure is designed as a U-shaped frame system (Fig. 9). Each beam span has a length of $5 \mathrm{~m}$. The plan geometry in this model has $5 \mathrm{~m}$ projection on the $\mathrm{Y}$ axis. However, there is not any projection on the $\mathrm{X}$-axis. In $\mathrm{U}$-shaped parametric model, the plan geometry does not have any projections on $\mathrm{X}$ axis. The total

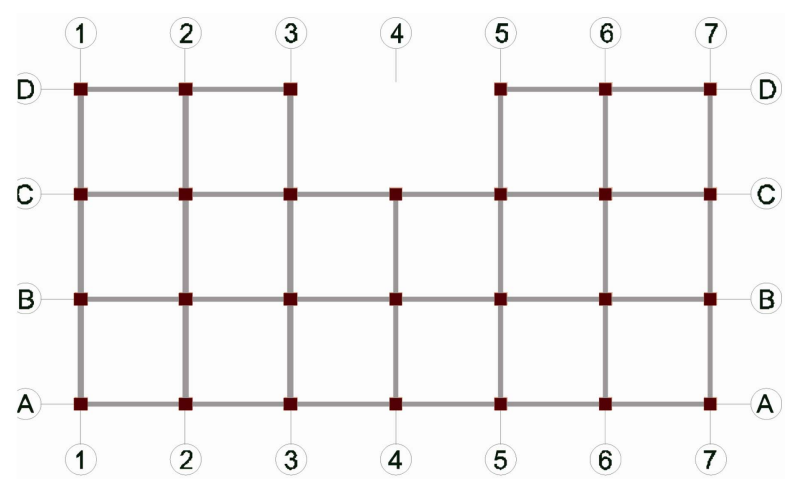

Fig. 9 Structural plans of parametric Model D 
plan dimensions of the model are $30 \mathrm{~m}$ on the X-direction and $15 \mathrm{~m}$ on the Y-direction. The A3 ratio in the U-shaped parametric model is calculated as $33 \%$ on the Y-axis. Consequently, as the limit ratio is exceeded, there is an A3 irregularity in the U-shaped parametric model (Model D) based on Y-axis. Furthermore, this model is symmetrical with respect to only the Y-axis.

According to the earthquake analysis report (refer to Table 2), the maximum value of effective storey drift in the U-shaped parametric model varies between $1.70 \mathrm{~mm}$ and $35.02 \mathrm{~mm}$. The limit values in terms of interstorey drifts and second order effect are not exceeded. These values not only increase from the one-storey model to the 20-storey model, but they also increase within the storeys of each sub-model of the U-shaped structure (Model D).

Based on the analysis, the maximum torsional irregularity coefficient $\left(\eta_{b i}\right)$ of 1.17 is obtained in all sub-models of U-shaped structure as in the $\mathrm{H}$-shaped structure, which shows that there is no torsional irregularity in this model. Moreover, there is not an increase or a decrease in the maximum torsional irregularity coefficients from the one-storey model to the 20-storey model. However, these coefficients decrease within the storeys of each sub-model of the U-shaped structure (Model D).

Soft storey irregularity coefficient $\left(\eta_{k i}\right)$ is within the normal ranges in the sub-models of the Ushaped structure, ranging between 1.52 and 1.68. The soft storey coefficient is agreeable because the coefficients remain under the limit coefficient of 2.00. The highest soft storey coefficient is calculated as 1.68 in the five-storey sub-model of the U-shaped structure. The highest soft storey coefficients are observed in the $1^{\text {st }}$ storey. Furthermore, it is realized that if the number of storeys in the U-shaped parametric model increases, it does not create a regular increase or decrease from the one-storey model to the 20-storey model or within the storeys of each sub-model of the U-shaped structure.

\subsection{Model E: Square plan geometry}

In this model, the storey gross area is $400 \mathrm{~m}^{2}$ and the plan geometry of the structure is designed as a square frame system (Fig. 10). Each beam span has a length of $5 \mathrm{~m}$. The model not only has symmetrical and regular plan geometry, but it also has regular rigidity distribution. Consequently, there is no A3 irregularity in the square parametric model (Model E).

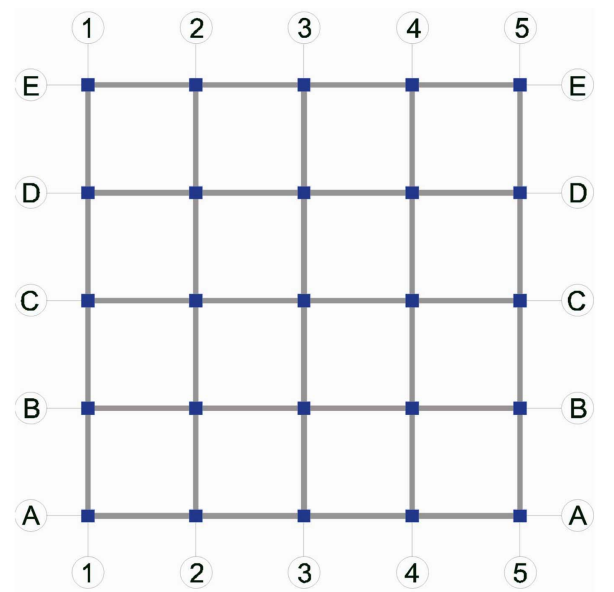

Fig. 10 Structural plans of parametric Model E 
According to the structural irregularities report, the maximum value of effective storey drift in the parametric Model E varies between $17.38 \mathrm{~mm}$ and $1.38 \mathrm{~mm}$. The limit values in terms of interstorey drifts and second order effect are not exceeded. These values increase from the onestorey model to the 20-storey model.

The analysis report shows that while the maximum torsional irregularity coefficient $\left(\eta_{b i}\right)$ is obtained as 1.11, the minimum torsional irregularity coefficient is obtained as 1.10 . The maximum torsional irregularity coefficient of 1.11 is obtained in the all models except one storey model, which shows that there is no torsional irregularity in the square-shaped parametric model (Model E).

Soft storey irregularity coefficient $\left(\eta_{k i}\right)$ is within the normal ranges in the sub-models of the Model E, ranging between 1.52 and 1.67. As the coefficients remain under the limit coefficient of 2.00 , the soft storey coefficient is agreeable in the square-shaped parametric model.

\section{Discussions and evaluations}

A set of five models, including four which have A3 or excessive projection dimensions and one with no projections, was analyzed during the study. The aim of this study was to investigate the seismic behavior of irregular plan geometries of different projection dimensions. All models were designed as frame systems. Irregular plan geometries were generated in three ways: symmetrical with respect to both axes ( $\mathrm{X}$ and $\mathrm{Y}$ ), symmetrical with respect to only one axis (X or $\mathrm{Y}$ ) and nonsymmetrical with respect to both axes ( $\mathrm{X}$ and $\mathrm{Y})$. The effects of the projection dimension ratio and the symmetry axis were evaluated. In the TEC (2007), a limit percentage of $20 \%$ is given for A3 irregularity. In this study, the importance of symmetry in the plan geometry and the ratio for A3 irregularity were examined. The obtained results (Table 2) were evaluated according to various criteria based on torsional irregularity coefficient, soft storey coefficient, effective storey drifts, relative storey drifts and second order effects.

The following conclusions can be reached after several numerical analyses concerning projection irregularity:

- The structural model that is symmetrical with respect to both axes shows the best seismic behavior. The changes in the torsional irregularity coefficients are illustrated in Fig. 11. The square plan geometry has no projections and is regular in terms of plan geometry. As it is also symmetrical with respect to both axes, it shows the best seismic behavior. Apart from other models, effective storey displacement shows lower values.

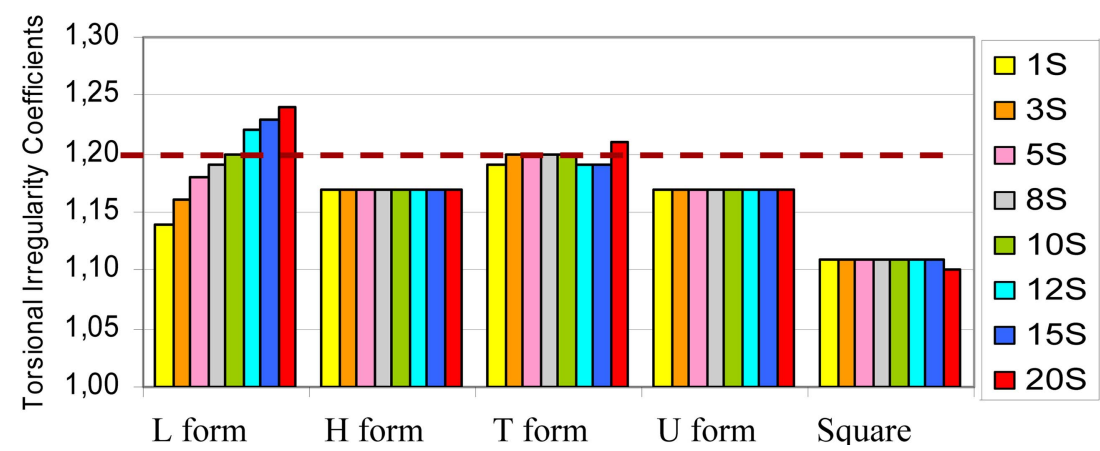

Fig. 11 Changes in torsional irregularity coefficients with the number of storey and different plan geometry 
- The H-shaped plan geometry is symmetrical with respect to both $\mathrm{X}$ and $\mathrm{Y}$ axes. However, it has a projection dimension of $48 \%$, which exceeds the limit coefficient of $20 \%$. On examining the maximum torsional coefficients for different storied parametric models of the H-shaped plan geometry, it can be observed that, as in the U-shaped model, the maximum torsional irregularity coefficients demonstrate a linear behavior and consistently display the value of 1.17.

- In terms of torsional irregularity, the U-shaped plan geometry shows similar seismic performance with the H-shaped plan geometry (Fig. 11). The U-shaped plan geometry has a projection dimension of $33 \%$ on the $\mathrm{Y}$ axis and therefore exceeds the A3 limit coefficient. However, it is symmetrical with respect to one axis. Considering both symmetry and the projection ratio, the torsional irregularity performance of the U-shaped plan geometry is similar to the H-shaped plan geometry, even though it is symmetrical with respect to only one axis. This is due to its projection dimension ratio being lower than that of the H-shaped plan geometry.

- The T-shaped plan geometry is symmetrical with respect to only the Y axis. On the other hand, it has an $\mathrm{A} 3$ ratio of $33 \%$ on the $\mathrm{X}$ axis and $50 \%$ on the $\mathrm{Y}$ axis, which exceeds the limit coefficient of $20 \%$. Investigation on the maximum torsional coefficients for different storied parametric models of the T-shaped plan geometry shows that torsional irregularity coefficients draw an uneven curve. In the 20-storey T-shaped parametric models, the maximum torsional irregularity coefficients begin to display an increasing linear curve with the maximum value of 1.21 .

- The L-shaped plan geometry is non-symmetrical and has a projection ratio of $60 \%$, which is three times the limit coefficient of $20 \%$. As a result, it presents the worst seismic performance among the models. Torsional irregularity coefficients depict a continuously increasing curve. In the 20-storey sub model of the L-shaped structure, the maximum torsional coefficient is calculated as 1.24.

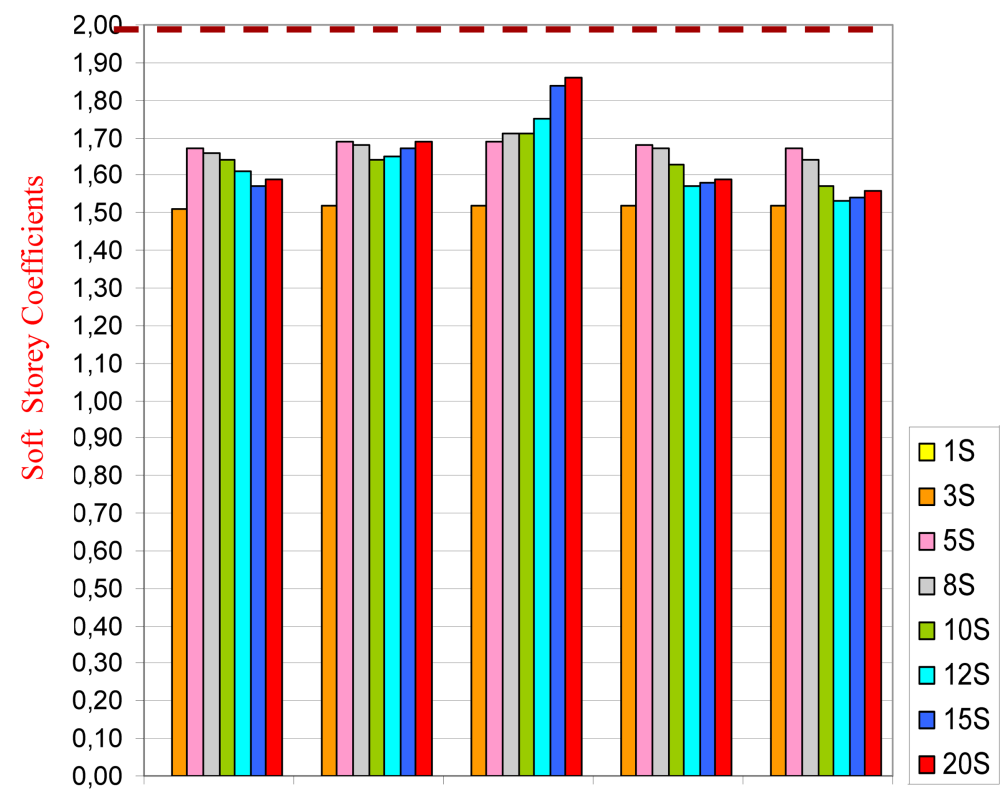

Fig. 12 Changes in soft storey irregularity coefficients with the number of storey and different plan geometry 


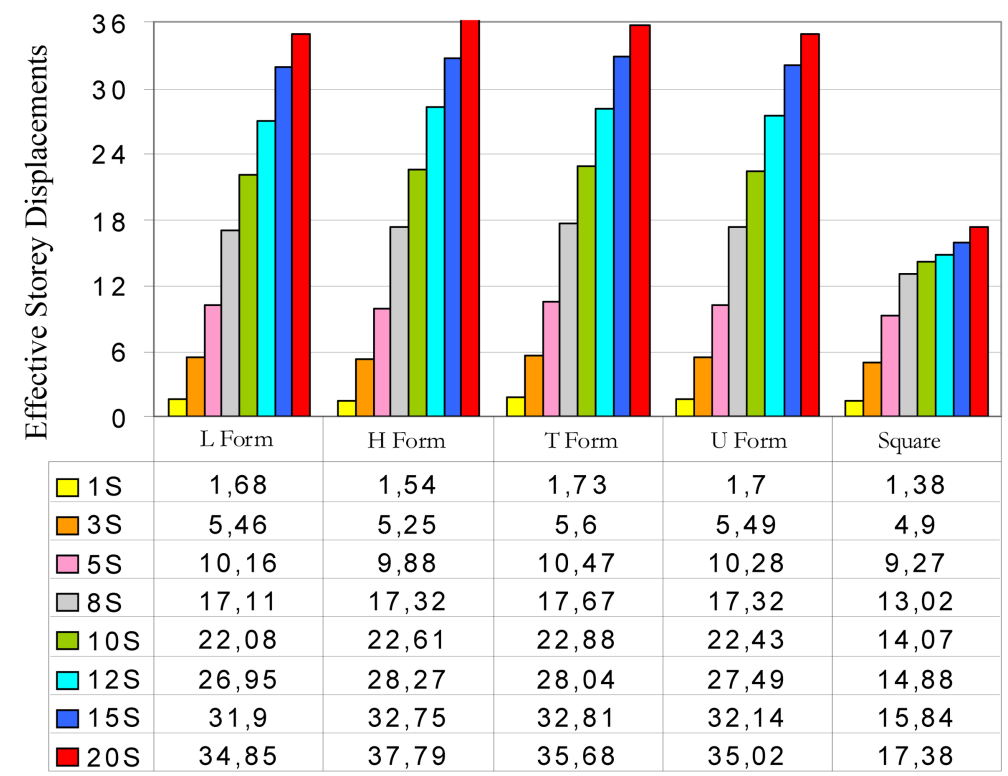

Fig. 13 Changes in effective storey displacements $(\mathrm{mm})$ with the number of storey and different plan geometry

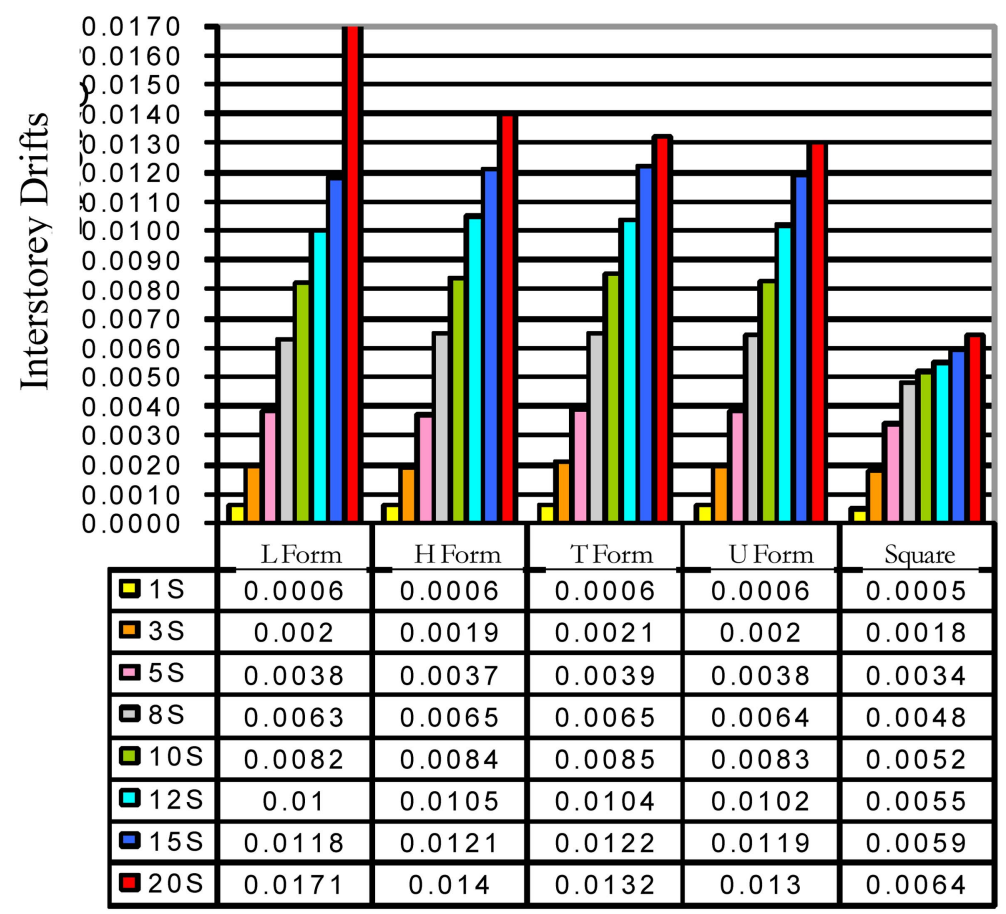

Fig. 14 Changes in interstorey drifts $(\mathrm{mm})$ with the number of storey and different plan geometry

- It is observed that all models demonstrated better seismic performance against earthquake loads subjected from the axis of symmetry.

- A soft storey irregularity is not observed in any model (Fig. 12). They are all below the limit 


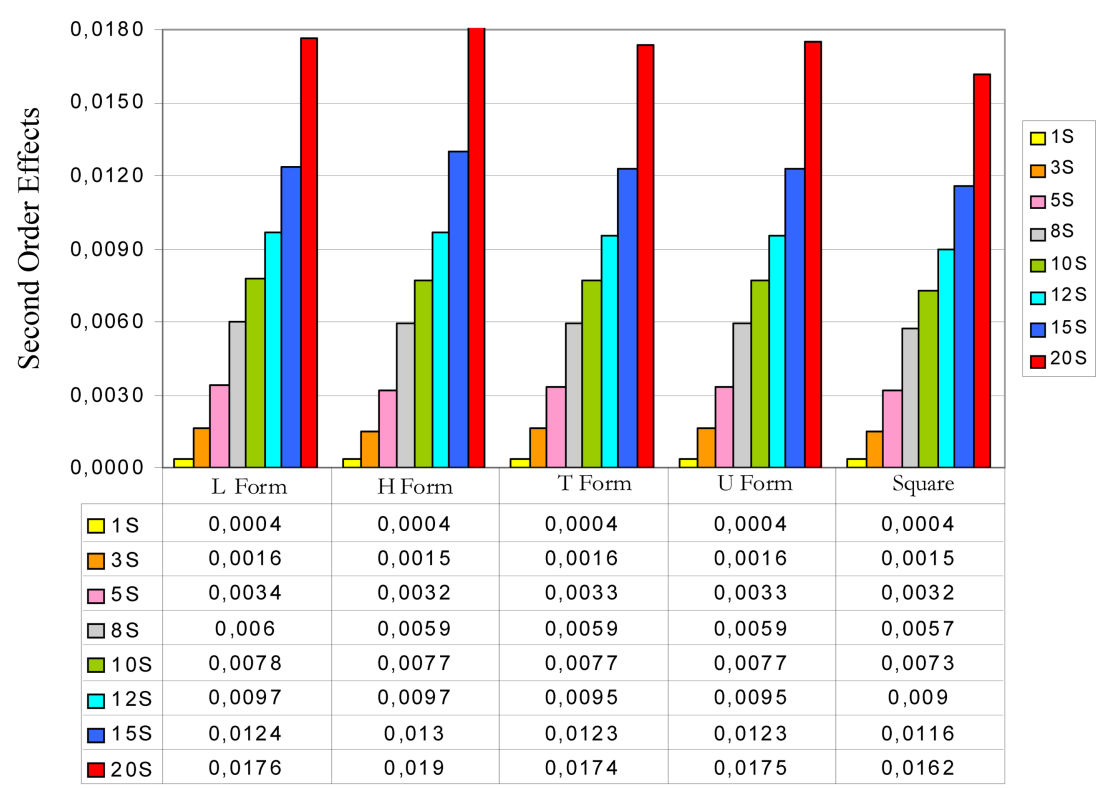

Fig. 15 Changes in second order effects with the number of storey and different plan geometry

value of 2.00, which is the given value for soft storey irregularity in TEC.

- The analyses demonstrate that structures of regular plan geometry that are also symmetrical with respect to the both axes show the best seismic performance.

- Square models have less storey displacements; their inter-storey drifts and second order effect coefficients are lower than those of other models (Figs. 13-15).

- The T- and U-shaped plan geometries are designed to have the same projection dimension ratio of $33 \%$, which is below the limit coefficient of $20 \%$. They are both symmetrical with respect to one axis (Y). On the other hand, although there is torsional irregularity in the T-shaped parametric model, the U-shaped parametric model does not have torsional irregularity. The Ushaped model has projections in plan only, on the Y-axis direction.

\section{Conclusions}

This study mainly concentrated on the effects of different plan geometries on earthquake performance of buildings. It consists of five main parametric model, and totally 40 models with the variations in the number of storey. Earthquake behaviors of buildings were examined in detail based on the variation in the number of storey, projection ratios and symmetry condition. The general results obtained from the analysis can be summarized as follows:

- It is clear that the best choice for the earthquake resistance is not constructing excessive projections, especially in the direction of the nonsymmetrical axis. If someone design buildings with projections in plan, they should be in line with the symmetry axis.

- Analysis show that a constant projection dimension value of $20 \%$ which is accepted for all plan geometries and its structural configuration, is not realistic. The interaction between projection ratio, projection direction and symmetry in plan geometry are much more important than the projection ratio. 
- In conclusion, the current regulations concerning the percentage allowed for projection dimensions imposed by the TEC (2007) should be altered to introduce changes corresponding to different plan geometries of models and their varying load-bearing systems.

\section{References}

Athanassiadou, C.J. (2008), "Seismic performance of R/C plane frames irregular in elevation", Eng. Struct., 30(5), 1250-1261.

Aziminejad, A. and Moghadam, A.S. (2005), "Performance of asymmetric single story buildings based on different conguration of center of mass, rigidity and resistance", Proceedings of the 4th European workshop.

Belmouden, Y. and Lestuzzi, P. (2009), "An equivalent frame model for seismic analysis of masonry and reinforced concrete buildings", Constr. Build. Mater., 23(1), 40-53.

Cagatay, I.H. (2005), "Experimental evaluation of buildings damaged in recent earthquakes in turkey", Eng. Fail. Anal., 12(3), 440-452.

Cagatay, I.H. (2009), “An example for earthquake resistant ideal building”, International Earthquake Symposium 2009, Kocaeli University, Kocaeli, August.

Cagatay, I.H., Beklen, C. and Mosalam, K.M. (2010), "Investigation of short column effect of RC buildings: failure and prevention", Comput. Concrete, 7(6), 523-532.

Charleson, A. (2008), Seismic design for architects: outwitting the quake, A.B.D., Burlington: Elsevier.

Dimova, S. and Alashki, I. (2003), "Seismic design of symmetric structures for accidental torsion", Bull. Earthq. Eng., 1(2), 303-320.

Ganjavi, B., Amiri, J.V., Amiri, G.G and Razavian, S.A. (2007), "Effect of seismic loading patterns on heightwise distribution of drift, hysteretic energy and damage in reinforced concrete buildings", J. Appl. Sci., 7(22), 3431-3441.

IdeCad (2010), İdeYap, Istanbul, Turkey.

Inan, T. (2010), The interaction of reinforced concrete skeleton systems and architectural form subjected to earthquake effects, Master Thesis, Izmir Institute of Technology.

Repapis, C., Zeris, C. and Vintzileou, E. (2006), "Evaluation of the seismic performance of existing RC buildings: II. A case study for regular and irregular buildings", J. Earthq. Eng., 10(2), 429-452.

Requirements for Design and Construction of Reinforced Concrete Structures (2000), Turkish Standards Institute (TS-500).

Sezen, H., Elwood, K.J., Whittaker, A.S., Mosalam, K.M., Wallace, J.W. and Stanton, J.F. (2000), Structural engineering reconnaissance of the August 17, 1999 Kocaeli (Izmit), Turkey, earthquake, PEER 2000/09, University of California, Berkeley.

Specification for Buildings to be Built in Seismic Zones 2007 (2007), Ministry Of Public Works and Settlement, Government of Republic of Turkey (TEC).

Stefano De, M. and Pintucchi, B. (2008), "A review of research on seismic behaviour of irregular building structures since 2002”, Bull. Earthq. Eng., 6(2), 285-308.

Sucuoglu, H. and Yilmaz, T. (2000), Duzce, Turkey: A city hit by two major earthquakes in 1999 within three months, Ankara, Turkey: Earthquake Engineering Research Center.

Takashi, H. (2011), "Appication of computational technologies to R/C structural analysis", Comput. Concrete, 8(1), 97-110.

Tezcan, S.S. and Alhan, C. (2001), "Parametric analysis of Irregular structures under seismic loading according to new Turkish earthquake code", Eng. Struct., 23(6), 600-609.

Tezcan, S.S. (1998), "Depreme dayankl tasarm İçin bir mimarn seyir defteri”, Turkiye Deprem Vakf Yaynlar No. TDV/KT 98-024. (in Turkish).

Zacek, M. (2002), Depreme dayanıkl yapı tasarımı ön proje apaması. (Ed. M. T. Akbulut). Türkiye, Istanbul: Yıldız Teknik Üniversitesi. (in Turkish). 